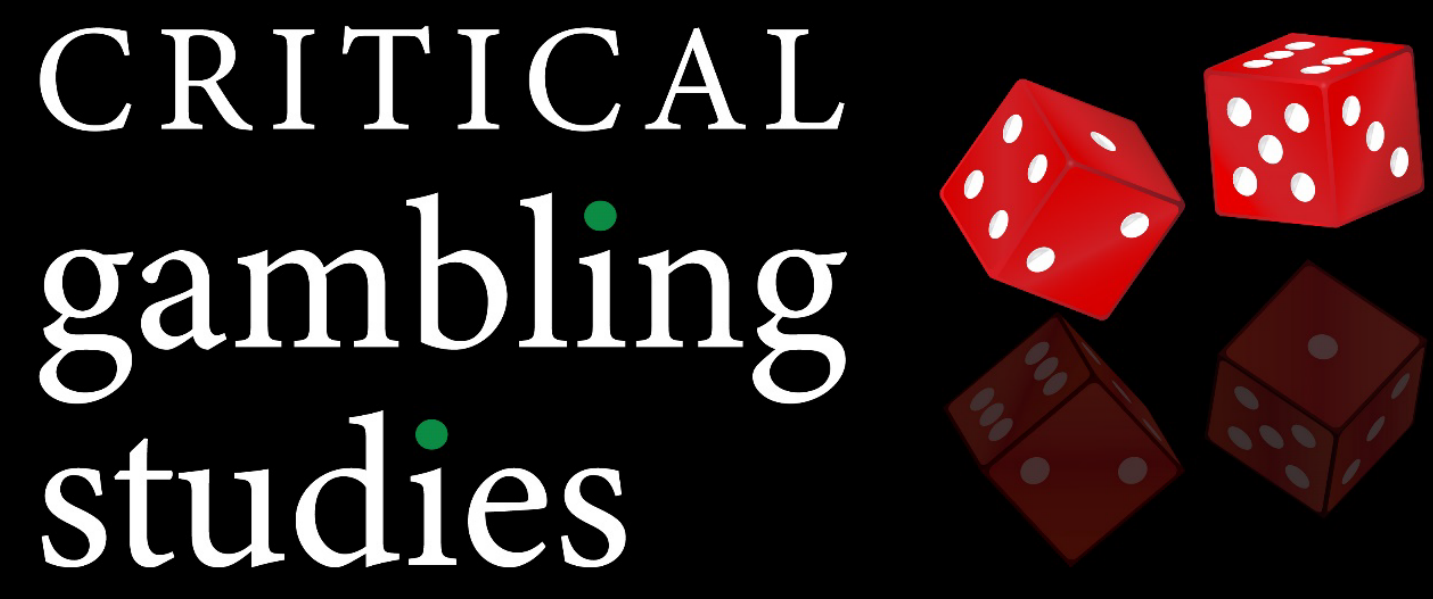

ISSN: 2563-190X. Available Open Access at https://criticalgamblingstudies.com

\title{
A Critical Review of the Scholarly Discourse on Gambling Disorder Treatment: Part 2
}

Iva Kosutic, Jeffrey Christensen, Theresa McDowell

APA Citation: Kosutic, I., Christensen, J., \& McDowell, T. (2022). A Critical Review of the Scholarly Discourse on Gambling Disorder Treatment: Part 2. Critical Gambling Studies, 3 (1), 47-57. https://doi.org/10.29173/cgs97

Article History:

Received 2021-02-05

Accepted 2021-08-11

Published 2022-03-07 


\title{
A Critical Review of the Scholarly Discourse on Gambling Disorder Treatment: Part 2
}

\author{
Iva Kosutic ${ }^{\mathrm{a}}$, Jeffrey Christensen ${ }^{\mathrm{b} 1}$, Theresa McDowell ${ }^{\mathrm{b}}$
}

\author{
a Partners in Social Research \\ ${ }^{\mathrm{b}}$ Lewis and Clark College
}

\begin{abstract}
This article presents a critical systematic review of the literature on disordered gambling treatment, with a focus on the "how" of treatment delivery. A review of six peer-reviewed research databases was performed, along with hand searches of select journals. Peer-reviewed articles that discussed or evaluated psychological and relational treatments of gambling disorder were selected for a review and coded independently by all members of the research team. The sample for this study included 445 articles that were published in the English language over the past 50 years, through June 2019. The sample included not only evaluations and case studies $(k=231)$ but also descriptive research $(k=49)$, meta-analyses $(k=10)$, and literature reviews $(k=155)$. The results showed that face-to-face, professionally facilitated treatment of individuals has remained the primary focus of problem gambling literature during the period under study. That said, a number of alternative treatment modalities have emerged, particularly in the last two decades. This includes increased reliance on technology (i.e., internet and telephone/text) as an adjunct to face-to-face treatment or as a means for delivering stand-alone professionally facilitated or self-directed interventions. Our discussion includes the benefits of these approaches as reflected in the literature while also situating findings within discourses on Western-dominated trends toward the use of technology, prioritization of efficiency, and individual focus in mental health treatment.
\end{abstract}

Keywords: Gambling disorder treatment, problem gambling treatment, disordered gambling treatment

Article History: Received February 5, 2021; Accepted August 11, 2022; Published March 7, 2022

Available Open Access from https://doi.org/10.29173/cgs97

\section{Introduction}

The scholarly discourse on gambling disorder (GD) treatment has rapidly increased over the past fifty years. The body of literature on GD treatment has expanded across conceptual articles to empirically validated forms of treatment, specialized interventions, and external therapeutic factors that influence positive client outcomes (Cowlishaw et al., 2014; Priester et al., 2016; Shaffer \& Martin, 2011). This trend in knowledge production reflects increased attention to GD requiring specialized treatment and gambling itself as a unique field of study that coincides with expanded access to gambling venues (i.e., online platforms, extended legalization of gambling) (Hayer et al., 2018). The growth of this specialized scholarly discourse makes this an opportune time to pause, review, and reflect (Porche, 2010) on the body of knowledge being created in the area of GD treatment.

In Part I of this study (Christensen et al., 2021), we focused on "what" has been included in the scholarly discourse on GD treatment. This included the type of GD knowledge that has been produced and treatment approaches that have been highlighted over time and across various regions of the world. In this article, we focus on "how" GD treatment has been described in scholarly discourse, again over time and world regions.

The research questions that guide Part II of this investigation are focused on GD treatment modalities and modes, as discussed in peer-reviewed journal articles. Questions include: What modalities and modes have been included in the professional discourse on psychological and relational approaches to GD treatment? And, how has the coverage of GD treatment modalities and modes changed over time, across article types and professional audiences, and by the country of the target population? These research questions reflect our interest in exploring how GD services have been delivered over time and across contexts.

\section{Related Literature}

A number of systematic reviews of the literature have addressed the effectiveness of various GD

\footnotetext{
${ }^{1}$ Corresponding author. Email: ichristensen@lclark.edu, Counseling Psychology Department Lewis and Clark College, Graduate School of Education and Counseling 0615 S.W. Palatine Hill Rd Portland, OR 97219
} 
treatments. These treatments range from psychological to psychopharmacology interventions, with CBT and motivational interviewing $(\mathrm{MI})$ receiving the most attention under the psychological interventions umbrella (Echeburua et al., 2017; Pasche et al., 2013; Rizeanu, 2015). A subset of these reviews is relevant to this study, including those that have centered on the delivery of GD treatment, including professionally delivered in-person and/or online treatment; peer support/recovery; self-guided interventions; and individual, family and/or group treatment. A brief overview of these studies yields some interesting trends.

First, it appears that professionally-directed psychological treatment for GD is generally beneficial. In 2014, Rash and Petry conducted a review of psychological treatments for GD, ranging from self-help and peer support approaches to more intensive, professionally delivered treatments. They found that professionally delivered approaches yielded better results than either wait-list controls or peer support treatments, such as Gamblers Anonymous (GA), in clients with more severe gambling problems. Comparisons of treatment models (e.g., cognitive compared to cognitive-behavioral interventions) did not demonstrate one model being more effective than others. Similarly, group and individually delivered therapies were equally effective. It is interesting to note that GD symptoms were shown to dissipate over time for treatment seekers, regardless of the modality or method of treatment delivery.

Second, internet-based interventions have shown promise as an auxiliary form of treatment for GD. Van der Mass and colleagues (2019) conducted a scoping review of internet-based interventions for problem gambling, covering a 10-year period between 2007 and 2017. A search of 6 research databases and 3 gray literature databases yielded 27 articles that met the review criteria. A majority of the studies used online interventions to modify in-person interventions, and though treatment access and flexibility were greater for individuals using internet-based treatments, attrition rates of online participants remained comparable to inperson attrition rates; admittedly, however, direct comparisons between in-person and online interventions were difficult due to inconsistent definitions and tracking of dropouts. The authors concluded that though online treatments showed potential, more research was needed to determine whether there was a deficit in rapport when compared with in-person treatments.

Third, self-directed approaches have been of growing interest given the high rates of dropout and relapse, as well as the fact that most of those suffering with a GD do not seek professional help. Abbott (2019b) reviewed self-directed interventions reported in articles published in 2017 and 2018. This literature review led to the conclusion that many individuals were able to reduce gambling without professional interventions and that a wide variety of self-directed interventions could decrease problem severity. In some cases, the effectiveness of self-directed interventions was similar to more traditional, professionally-delivered services.

As part of the same review, Abbott (2019a) investigated professionally delivered interventions. He found that among the wide variety of interventions, cognitive-behavioral therapies (CBT) and motivational enhancement interventions were the most commonly studied, with both demonstrating positive effects. For interventions that were Internet-based, CBT was the most common framework, with those interventions showing a positive effect on reducing gambling behavior and gambling related problems. He concluded that further research comparing the different types and intensities of interventions delivered face-to-face, online, and other formats could assist future implementations of cost-effective, stepped care services.

It is interesting to note that although treatment for GD appears to be effective in general, studies that have compared different treatment models (e.g., CBT compared with $\mathrm{MI}$ ) have been unable to determine significant differences or identify what specific interventions produced the intended desired effect in clients (Oei et al., 2010; Oei et al., 2018; Smith et al., 2013; Toneatto \& Gunaratne, 2009). This perhaps further highlights the importance of considering how GD treatment is delivered.

\section{Methods}

This study was part of a larger project that involved a comprehensive review of the literature on psychological and relational approaches to GD treatment. A detailed description of the methods is available elsewhere (Christensen et al., 2021). In short, the review encompassed peer-reviewed articles that were published in the English language and that described case studies and evaluations of GD treatment; descriptive research with explicitly articulated implications for treatment; literature reviews and meta-analyses; and descriptions of novel approaches to treatment. Considering the overarching goal of the study to provide a broad characterization of the scholarly discourse of relational and psychological approaches to GD treatment, no restrictions were placed on intervention type, research design, or participant characteristics.

Two strategies were employed to identify articles for the review. First, we systematically searched six electronic databases-1) PsychNet, 2) PubMed, 3) SocINDEX, 4) Psych and Behavioral Sciences (through Ebsco), 5) Social Science Citation Index, and 6) Academic Search Premier-using pre-defined terms related to gambling and treatment: (problem* OR pathology* OR disorder*) AND gambl* AND (treatment* OR intervention* OR program*OR outcome* OR evaluation* OR provider). These terms were consistent among all six databases and accounted for all fields, including titles, abstracts, subject terms, and medical subject headings. Second, we hand-searched reference 
sections of published literature reviews and contents of select peer-reviewed journals, looking for relevant journal articles that were published through June 2019. We did not consult grey literature because our goal was to characterize the professional discourse on GD treatments, as carried out through publications, rather than to synthesize the evidence of treatment effectiveness, as is the case with meta-analyses.

The search of electronic databases yielded 9,364 articles, 4,267 of which were duplicates. The handsearch yielded additional six articles. Following the removal of duplicates, 5,103 unique articles were screened independently by two reviewers, with input from a third reviewer. The screening involved scanning article titles and abstracts for relevance. Articles were coded as "not relevant" if they "covered obviously unrelated topics such as oral health and medicine; if they centered on gaming and other behavioral addictions; and, if they focused on pharmacological treatment of problem gambling without a psychological or relational component" (Christensen et al., 2021, p. 37). A total of 684 articles were identified as possibly relevant for the project, and full text was obtained for all of them. At least two reviewers scanned the full-text of each article to ascertain its relevance. Frequent meetings were held to compare screening decisions and to discuss differences in opinion. Final decisions were reached through consensus. Articles were coded as "not relevant" at this stage if they "described prevention interventions; public health interventions; study protocols; instrument development research; prevalence research; methodological research; descriptive research without a section on implications for treatment; interventions that involved pharmacological treatment without a psychological component; interventions completed in samples that did not include problem gamblers; and commentaries, errata, and book reviews" (Christensen et al., 2021, p. 37). Altogether, 239 articles were coded as "not relevant" and were excluded from further review; this includes one article that was withdrawn but remains indexed in electronic databases. A total of 445 articles were included in the review.

We used a coding sheet to code the relevant articles. The sheet included fields pertaining to bibliographic information; article type (see Table 1); treatment model (see Table 2); sample description for evaluation research (i.e., country of the target population); treatment modality (group, couple, concerned significant others); treatment mode (face-to-face vs. technologymediated); treatment length (i.e., treatments labeled in journal articles "brief" or "minimal"); and the primary professional audience (based on the journal's title and the description of its aims and scope via the journal's online homepage). Codings were cross-checked by all members of the team and differences in opinion were resolved through joint review of full text.

\section{Results \\ Modalities and Modes Over Time}

All approaches to GD treatment include the person with problem gambling. Besides the problem gambler, some approaches include family members and concerned significant others (CSOs), the couple unit of which the problem gambler is a part, and groups comprising multiple individuals seeking treatment or support. During the 50-year period under study, these relational approaches to treatment were discussed in close to half (44\%) of peer-reviewed articles on GD treatment; however, family/CSOs and couples in treatment occupied a relatively small part of this literature (17\%). More specifically, of 445 articles that were coded for this study, about $8 \%$ discussed couples therapy; just over $11 \%$ reviewed, or studied, the inclusion of family/CSOs in treatment; close to $17 \%$ discussed either couples or family/CSOs; and over onethird (35\%) covered group treatments (Table 1). The proportion of articles that discussed relational approaches (broadly defined to include family/CSOs, couples, and groups) was significantly greater among literature reviews than among evaluation studies $\left(68 / 106\right.$ vs. $\left.86 / 231, X^{2}(1)=21.2, p<0.001\right)$, thus suggesting that relational approaches were much talked about but little studied. Namely, of 106 literature reviews, about $22 \%$ discussed family/CSOs and couples in treatment, and $58 \%$ discussed group approaches. By contrast, among 231 evaluation and case study articles, about $14 \%$ explored the inclusion of family/CSOs or couples in treatment, and over a quarter (27\%) explored group approaches. 
Table 1. Count of Articles: by Article Type, Modality, Mode, and Length of Treatment

\begin{tabular}{|c|c|c|c|c|c|c|c|c|c|}
\hline & \multicolumn{3}{|c|}{ Modality } & \multicolumn{3}{|c|}{ Mode } & \multirow{2}{*}{$\frac{\text { Length }}{\text { Brief }}$} & \multicolumn{2}{|c|}{ All Articles } \\
\hline & CSO & Couple & Group & Web & Tel & Biblio & & $n$ & $\%$ \\
\hline \multicolumn{10}{|l|}{ Evaluation Research } \\
\hline Randomized controlled trial & 3 & 3 & 19 & 10 & 12 & 19 & 20 & 70 & 15.8 \\
\hline Quasi-experimental & -- & 3 & 8 & -- & 2 & 2 & 1 & 18 & 4.0 \\
\hline Outcome evaluation & 10 & 3 & 27 & 8 & 11 & 7 & 7 & 85 & 19.1 \\
\hline Process evaluation & 6 & 3 & 8 & 6 & 3 & 2 & 3 & 23 & 5.2 \\
\hline Case study & 3 & 2 & 3 & 1 & 2 & 1 & 2 & 35 & 7.9 \\
\hline Evaluation Research Subtotal & 22 & 14 & 65 & 25 & 30 & 31 & 33 & 231 & 52.0 \\
\hline Descriptive research & 5 & 1 & 9 & 2 & 1 & 1 & -- & 49 & 11.0 \\
\hline Meta-analysis & -- & -- & 3 & 3 & 2 & 3 & 1 & 10 & 2.2 \\
\hline Literature review & 17 & 12 & 62 & 23 & 21 & 23 & 26 & 106 & 23.8 \\
\hline New approach to treatment & 6 & 7 & 16 & -- & 2 & -- & -- & 49 & 11.0 \\
\hline Total & 50 & 34 & 155 & 53 & 56 & 58 & 60 & 445 & 100.0 \\
\hline
\end{tabular}

Note. $\mathrm{CSO}=$ treatment including family members or concerned significant others of the person with gambling disorder; Couple = treatment including romantic partners; Group = group therapy; Web = use of Internet in treatment; Tel = use of telephone in treatment; Biblio = use of workbooks, pamphlets, and books in treatment. Brief = brief or minimal contact approaches.

Not surprisingly considering the overall growth of the literature, the total number of articles that discussed family/CSOs in treatment, couples therapy, or group therapy increased markedly over the 50-year period under study, as the top left panel in Figure 1 shows. Relative to the number of articles that were published during each decade, however, interest in relational approaches has decreased over time. Namely, the proportion of articles that discussed relational approaches peaked in the 1980s, followed by sharp declines in subsequent decades (Figure 1, top right panel). Of all articles that were published in the 1980s, over a quarter (28\%) discussed family/CSOs or couples therapy, and close to two-thirds (62\%) discussed group therapy. By the second decade of the $21^{\text {st }}$ century, those proportions fell to about $14 \%$ for family/CSOs or couples in treatment, and under one-third (31\%) for group therapy.

Traditionally, the treatment of GD involved face-toface meetings between the problem gambler and the treatment provider. In a departure from this tradition, the past 50 years saw a rise in technology-mediated approaches as a supplement to or in place of face-toface contacts. On the whole, close to a quarter (24\%) of all articles in this study discussed treatments involving the use of either Internet, telephone, or workbooks, pamphlets, and books. The number of articles that discussed technology-mediated interventions increased over time, as the bottom left panel in Figure 1 shows. Additionally, these articles occupied an increasingly greater proportion of the literature produced during each subsequent decade, starting with none in the 1960s and 1970s and ending with between $16 \%$ and $21 \%$, for each of the three technology-mediated approaches, in the 2010s (Figure 1, bottom right panel). Notably, any of these approaches was discussed in over a third (35\%) of the articles published in the 2010 s. 
Figure 1. Articles Over Time: by Treatment Modality and Mode $(k=445)$

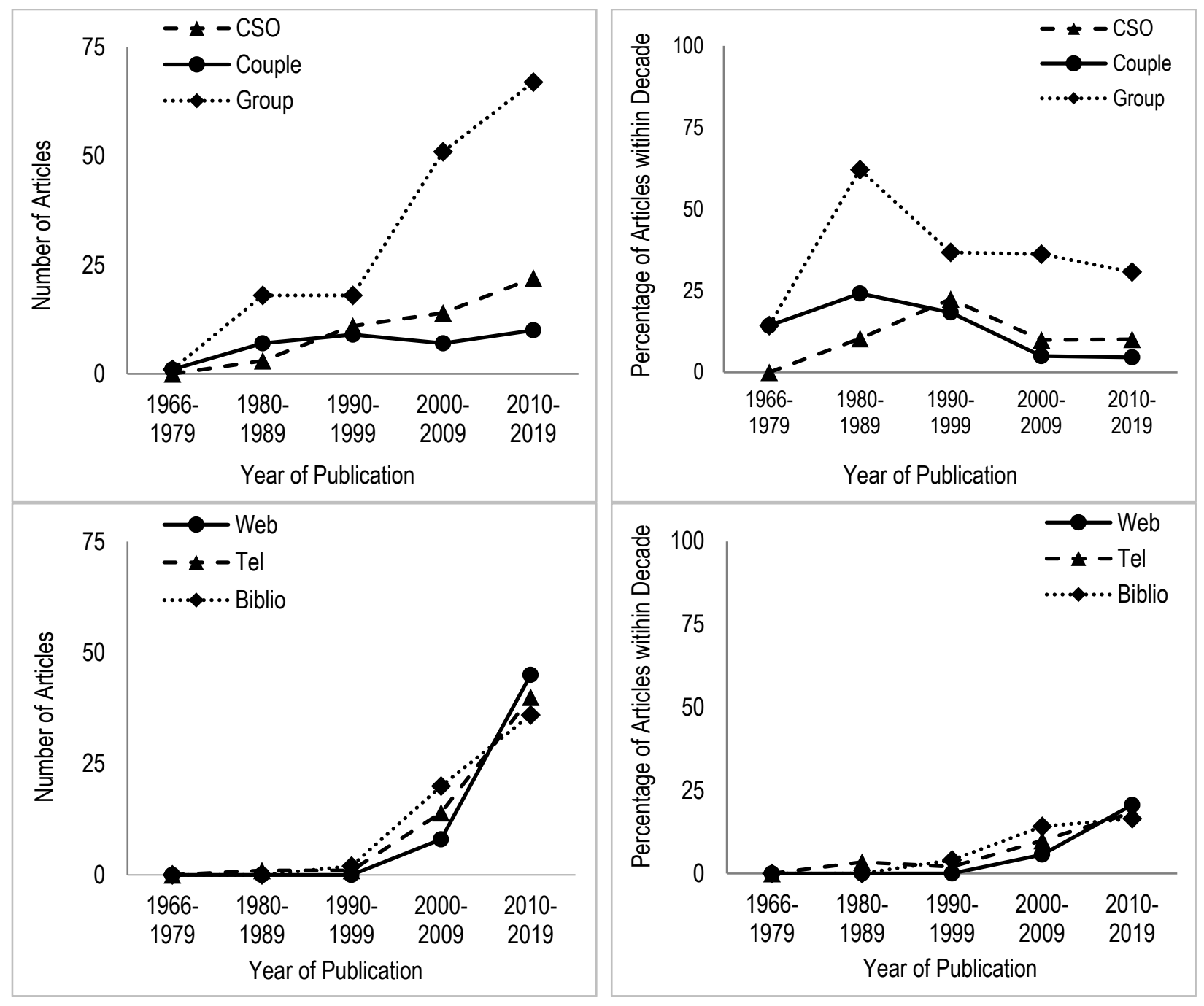

Note. $\mathrm{CSO}=$ treatment including family members or concerned significant others of the person with gambling disorder; Couple = treatment including romantic partners; Group = group therapy; Web = use of Internet in treatment; Tel = use of telephone in treatment; Biblio = use of workbooks, pamphlets, and books in treatment.

\section{Article Characteristics Over Time}

Another tradition in psychological treatment is a relatively large number of contacts between the problem gambler and the treatment provider. Contrasting this tradition are brief or minimal contact interventions, which involve smaller amounts of professional time and resources than is typical of traditional interventions-usually fewer than five sessions (Dickerson et al., 1990; Petry, 2009). Overall, over $13 \%$ of all articles discussed brief treatments. Over the 50-year period under study, the number of these articles grew steadily (Figure 2, top left panel), as did their representation in the literature produced during each decade (Figure 2, top right panel). More specifically, within each decade the proportion of articles that discussed brief treatments grew from none in the 1960s, 1970s, and 1980s to just under one-fifth in the second decade of the $21^{\text {st }}$ century.

Traditionally, professionals have been involved in the design and delivery of GD treatment. Self-directed interventions buck this tradition. Designed by professionals, as is the case in personal feedback interventions, or by lay people, as is the case in Gamblers Anonymous, self-directed treatments have been discussed as both adjuncts to professionallydelivered interventions and stand-alone approaches. Overall, close to one-third (29\%) of articles that included sufficient information for classifying the mode of delivery discussed self-directed interventions: under $10 \%$ discussed only self-directed interventions, and over one-fifth (22\%) discussed both self-directed and professionally-delivered treatments. As the bottom left panel in Figure 2 shows, there was an increase over time in the number of articles that discussed self-directed treatments-both with and without the mention of professionally-delivered interventions. Proportionally within each decade, articles discussing self-directed treatments surged in the 1980 s, followed by a slump in the 1990s and a gradual rise over the first two decades of the $21^{\text {st }}$ century (Figure 2 , bottom right panel). It is 
also worth noting that the proportion of articles that discussed Gamblers Anonymous and other 12-step approaches decreased with each decade following the 1980s. By contrast, personalized feedback interventions emerged in the 2000s and grew precipitously in the 2010s.

Figure 2. Articles Over Time: by Length of Treatment and Delivery $(k=445)$
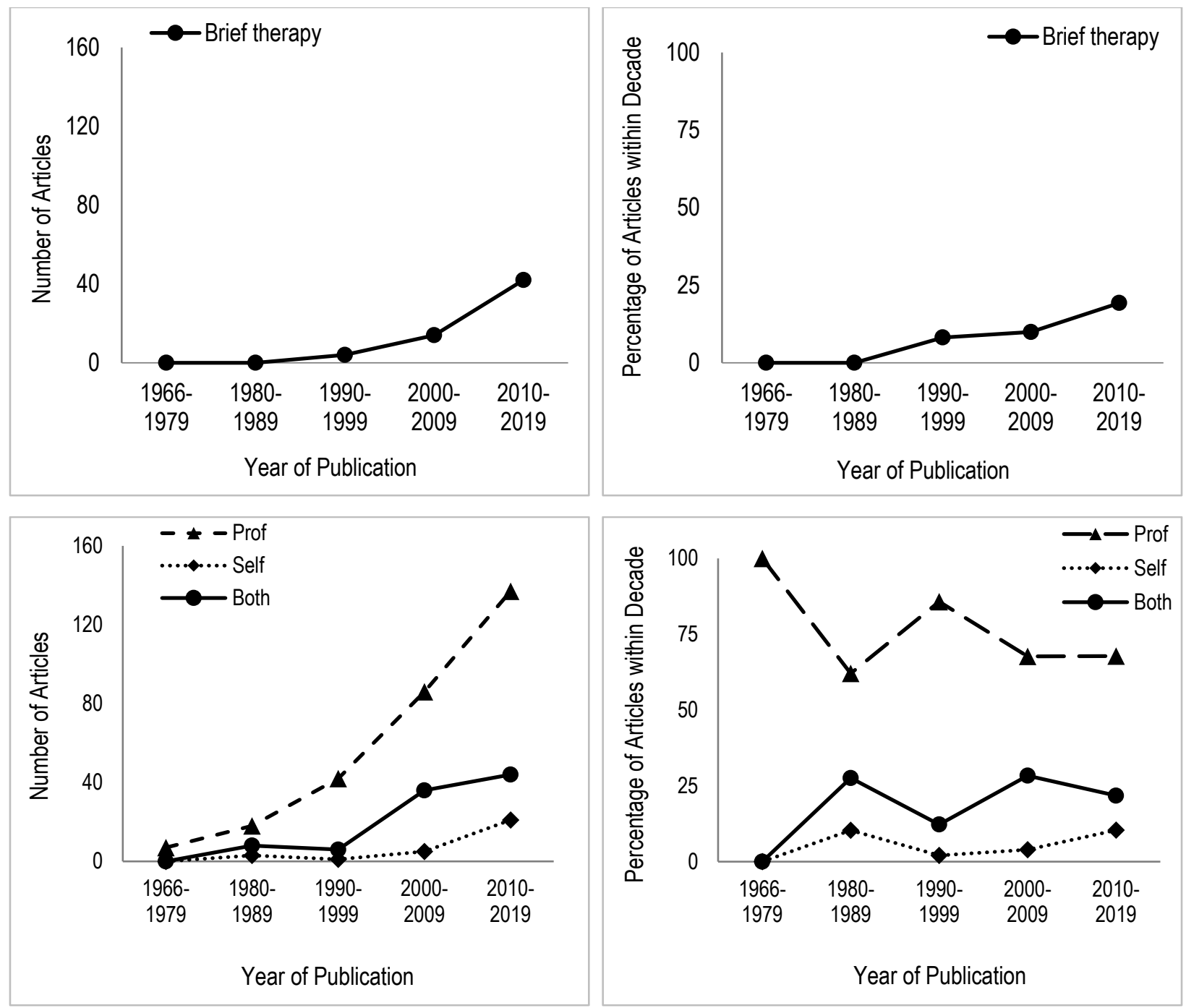

Note. Brief = brief or minimal contact approaches. Prof $=$ professionally-delivered treatment. Self $=$ self-directed treatment. Both $=$ both professionally-delivered and self-directed treatments. Thirty articles did not include sufficient information to reliably classify treatment delivery as professional, self-administered, or both; 415 articles provided sufficient information to determine the mode of delivery.

\section{Modalities and Modes Across Audiences}

Table 2 shows the distribution of articles by modality and mode of treatment across professional audiences. Close to one-third (32\%) of all articles were published in the journals directed primarily at gambling treatment providers. This was followed by psychologists, multidisciplinary audiences, psychiatrists, mental health professionals, physicians and nurses, and other professionals. Several patterns in Table 2 are interesting to note. First, inclusion of family/CSOs and couples in treatment was especially prominent in the literature for gambling treatment providers $(k=30 / 141,21 \%)$ as compared with the articles targeting other professionals. In contrast, family/CSOs and couples were discussed in few articles $(k=5 / 71,7 \%)$ directed at psychologists. Second, technology-mediated interventions were especially prominent in the literature targeting psychologists $(k=25 / 71,35 \%)$ relative to the other bodies of literature. Conversely, discussion of technology-mediated interventions was relatively sparse among articles targeting psychiatrists ( $k=10 / 61,16 \%)$. Third, brief treatments were especially pronounced in the articles directed at psychologists ( $k$ $=21 / 71,30 \%$ ) relative to all other articles. 
Table 2. Count of Articles: by Audience, Modality, Mode, and Length of Treatment

\begin{tabular}{|c|c|c|c|c|c|c|c|c|c|}
\hline & \multicolumn{3}{|c|}{ Modality } & \multicolumn{3}{|c|}{ Mode } & \multirow{2}{*}{$\begin{array}{c}\text { Length } \\
\text { Brief }\end{array}$} & \multicolumn{2}{|c|}{ All Articles } \\
\hline & CSO & Couple & Group & Web & Tel & Biblio & & $N$ & $\%$ \\
\hline Gambling treatment providers & 21 & 14 & 43 & 17 & 15 & 15 & 13 & 141 & 31.7 \\
\hline Psychologists & 2 & 4 & 24 & 9 & 15 & 20 & 21 & 71 & 16.0 \\
\hline Multidisciplinary & 6 & 3 & 23 & 11 & 9 & 9 & 8 & 66 & 14.8 \\
\hline Psychiatrists & 10 & 3 & 24 & 4 & 6 & 5 & 8 & 61 & 13.7 \\
\hline Mental health professionals & 3 & 3 & 16 & 5 & 4 & 4 & 5 & 49 & 11.0 \\
\hline Physicians, nurses & 4 & 1 & 12 & 6 & 5 & 4 & 3 & 24 & 5.4 \\
\hline Social workers & 2 & 1 & 4 & -- & 1 & -- & 1 & 13 & 2.9 \\
\hline Addiction specialists & -- & 1 & 7 & 1 & 1 & 1 & 1 & 8 & 1.8 \\
\hline Family therapists/counselors & 2 & 4 & 1 & -- & -- & -- & -- & 6 & 1.3 \\
\hline Hypnotists & -- & -- & -- & -- & -- & -- & -- & 3 & 0.7 \\
\hline Other & -- & -- & 1 & -- & -- & -- & -- & 3 & 0.7 \\
\hline Total & 50 & 34 & 155 & 53 & 56 & 58 & 60 & 445 & 100.0 \\
\hline
\end{tabular}

Table 3. Count of Evaluation Research Articles: by Country of Target Population

\begin{tabular}{|c|c|c|c|c|c|c|c|c|c|}
\hline & \multicolumn{3}{|c|}{ Modality } & \multicolumn{3}{|c|}{ Mode } & \multirow{2}{*}{$\frac{\text { Length }}{\text { Brief }}$} & \multicolumn{2}{|c|}{ All Articles } \\
\hline & CSO & Couple & Group & Web & Tel & Biblio & & $n$ & $\%$ \\
\hline Australia & 6 & 1 & 6 & 9 & 7 & 2 & 5 & 45 & 19.5 \\
\hline Canada & 4 & 5 & 9 & 5 & 9 & 18 & 10 & 45 & 19.5 \\
\hline United States & 2 & 1 & 17 & 1 & 4 & 6 & 12 & 44 & 19.0 \\
\hline Spain & 1 & 2 & 9 & 0 & 0 & 0 & -- & 19 & 8.2 \\
\hline Nordic countries & 0 & 1 & 5 & 5 & 5 & 1 & 2 & 13 & 5.6 \\
\hline Asian countries & 1 & 0 & 5 & 1 & 0 & 1 & 1 & 9 & 3.9 \\
\hline Germany & 3 & 1 & 2 & 2 & 0 & 0 & -- & 8 & 3.5 \\
\hline United Kingdom & 1 & 0 & 3 & 1 & 1 & 0 & -- & 7 & 3.0 \\
\hline New Zealand & 0 & 0 & 0 & 0 & 3 & 2 & 2 & 5 & 2.2 \\
\hline Other countries & 1 & 1 & 3 & 1 & 0 & 0 & -- & 6 & 2.6 \\
\hline Country not specified & 3 & 2 & 6 & 0 & 1 & 1 & 1 & 30 & 13.0 \\
\hline Total & 22 & 14 & 65 & 25 & 30 & 31 & 33 & 231 & 100.0 \\
\hline
\end{tabular}

\section{Modalities and Modes Across Countries}

Table 3 shows the distribution of evaluation research articles across the countries of target populations, separated out by the modality and the mode of treatment. Samples from Australia, Canada, and the United States of America were best represented in evaluations and case studies. This was followed by samples from Spain, the Nordic countries, Asian countries, Germany, the United Kingdom, New Zealand, and other countries.

Among articles that discussed the inclusion of family/CSOs in treatment, the most numerous were 
those with samples from Australia, Canada, and Germany. Samples from Canada and Spain were best represented among articles that discussed couples therapy, and samples from the United States of America, Canada, and Spain were best represented among articles that discussed group therapy.

Among articles that discussed Internet-based treatments, samples from Australia, Canada, and the Nordic countries were the most common. The use of telephone in treatment was discussed most in articles with samples from Canada, Australia, the Nordic countries, and the United States of America. Similarly, the use of workbooks and books in treatment was most frequently discussed in articles with samples from Canada and the United States of America. Lastly, the United States of America, Canada, and Australia were best represented among articles that discussed brief, or minimal contact, treatments.

\section{Discussion}

This study focused on the "how" of problem gambling treatment over the past 50 years. Face-toface, professionally facilitated treatment of individuals has remained the primary focus of problem gambling literature across time. That said, a number of alternative treatment modalities have emerged, particularly in the last two decades. This includes increased reliance on technology (i.e., Internet and telephone/text) as an adjunct to face-to-face treatment or as a means to deliver stand-alone professionally-facilitated or selfdirected interventions. Bibliotherapy interventions have also seen a rise in use during this period.

These trends make sense given the increasing availability of technology and electronic access to knowledge in most places in the world, as well as the subsequent development of online mental health interventions in general (Barak \& Grohol, 2011; Richards, 2013). Access to information and psychological interventions via the use of technology may reduce personal and social barriers to treatment (e.g., convenience, anonymity), as well as geographical barriers to face-to-face sessions. It is interesting to note that a higher regional percentage of literature focusing on internet and telephone interventions has come from Australia, Canada, and Nordic countries. One possible explanation for this trend is that these types of interventions provide access in societies with advanced technology and geographies that include vast land masses and/or inhospitable climates.

The literature on face-to-face problem gambling services also reflects a focus on shortening overall time in treatment. This is demonstrated by a steady increase in brief treatments over the past 30 years. Treatment outcomes-the measures of treatment success-have also tended to be limited, with the primary goal being behavioral, i.e., decreased gambling. Many of the manualized, evidence-based treatments that are included in the outcome literature are goal- and timelimited. Overall, there appears to be an evolving effort to identify specific, focused interventions that effectively reduce gambling problems in the shortest amount of time possible. Trends toward the use of technology mirror trends toward decreasing the need for professional involvement in treatment. This extends to recent use and evaluation of brief personalized feedback interventions (Peter et al., 2019) that rely on single or very limited in-person, telephone and/or webbased interactions. These include interventions that are professionally facilitated, self-directed, or a combination of both.

The literature highlights many benefits to developing and offering multiple treatment modalities and diverse options for recovery. It is important, however, to consider additional unfavorable consequences of increased reliance on technology in GD treatment, particularly when technology is viewed as a way to increase treatment efficiency. This may be particularly important as evidence shows there are likely different "types" or pathways to disordered gambling that require different approaches to change (Blaszczynski \& Nower, 2002). For example, openaccess, Internet-based psychoeducation may also have a positive effect on the majority of those who reduce or stop gambling without professional help (Abbott, 2019b). Those not inclined to enter traditional treatment may be willing to engage in self-paced, online activities that lead to better understanding and more self-control of gambling. Minimal or brief intervention may be adequate for those whose gambling is primarily a learned habit. Those with additional underlying trauma, psychological issues, relational problems, and co-occurring addictions are likely to require more intensive treatments.

The literature in this review reflects a continued interest in group treatment for individuals struggling with problem gambling; however, the sharp rise in the percentage of articles on group therapy in the 1980s was followed by a lower percentage of articles on the topic over the next several decades. This trend is also reflected in attention to treatment of couples, again with the percentage of articles spiking in the 1980s and losing momentum since that time. Involvement of concerned others reflects a similar trajectory with the largest percentage of articles on this topic being published in the 1990s. The lack of attention to treating couples, families, and concerned others is surprising in many ways, particularly given the frequency of inclusion in literature reviews and widely accepted acknowledgment of the negative impact of problem gambling on others (Abbott et al., 1995).

With a few exceptions, the literature has not focused on including children in treatment in spite of general awareness of the negative effects of parental gambling (Doussa et al., 2017). One possible explanation may be the limited focus of outcome goals mentioned above. If the primary measure of success in problem gambling treatment is to decrease the gambling behavior of an individual, there may be less interest in goals that include the wellbeing of couples, families, and/or networks of concerned others. If this is the case, brief, 
individualized treatments may help alleviate the individual and indirect social burden of gambling without addressing the cost to relationships and to the wellbeing of those affected by another's gambling. Somatic complaints, divorce, missed work, poor school performance, youth and familial legal problems, and psychological distress are among a long list of social, economic, and health costs incurred by a loved one's gambling (Abbott et al., 1995). The focus on individual treatment over relational approaches also persists in spite of evidence that involvement of family and concerned others improves length of engagement and treatment outcomes (Jiménez-Murcia et al., 2017).

Finally, it is important to draw attention to where, by whom, and for whom knowledge is being produced regarding treatment for disordered gambling. One of the limitations of this study was that only articles written in English were included for review. That said, the vast majority of literature on problem gambling treatment is produced in the English language and most professional knowledge to date has been produced and published in Australia, Canada, and the United States of America. Research participants are most often from these countries as well. English language literature may be skewed toward Western worldviews, including treatment modalities and goals. Consider as a case in point the contrast between Western treatment approaches such as cognitive behavioral therapy and a Mâori-centered approach (Herd, 2006) that relies on an Indigenous, decolonizing framework created by and for a community of women struggling with gambling.

Treatment literature is also created and disseminated to specific professional audiences. It makes sense that problem gambling treatment providers were the most frequent target audience for this body of literature, particularly as the field has developed as a specialization over time. This target audience was followed in frequency by psychologists, multidisciplinary audiences, psychiatrists, and mental health professionals. A possible limitation of this study could be the exclusion of grey literature for our review. We believe grey literature is an important part of general academic discourse and its exclusion from this study was because our goal was to characterize what has been published for professional audiences. In concert with the lack of attention to couples and families mentioned above, family therapists were among the least likely audiences to be addressed via literature on problem gambling treatment. Publication patterns suggest the need to expand the production and dissemination of treatment modes and modalities originating from non-Western perspectives and to include a broader audience of professionals in developing and sharing expertise in problem gambling treatment.

\section{Conclusion}

Legalized gambling is a valuable source of revenue for many countries and gambling proceeds are often used for the public good. The cost of this resource and pastime, however, includes the collective burden of problem gambling and the responsibility to mitigate this burden often falls on the government and/or under-resourced treatment communities. Finding effective and efficient treatments make sense for all involved, including the individual seeking treatment, overworked treatment professionals, and treatment funders. Approaches that rely less heavily on professional intervention to decrease problem gambling are attractive, particularly when they demonstrate effectiveness in decreasing gambling behavior. Streamlining and compartmentalizing treatment to focus on narrow gambling-focused goals and working only with individuals may limit long-term efficacy however. Developing more holistic and systemic approaches that privilege not only personal but also relational and community well-being might improve other areas of life and mitigate the broad impact of gambling problems, while decreasing gambling behavior.

This review raises a number of considerations for future research. First, there is a significant gap between the literature on relational approaches to gambling treatment and future studies could investigate the importance of including concerned others (e.g., families, spouses, loved ones, friends, children) with treatment success and the wellbeing of those affected by gambling. Second, little attention has been paid to developing culturally relevant practices or considering the impact of dominant Western and Euro-centered approaches on members of non-Western, nondominant cultural groups and future studies exploring GD treatment would benefit from not limiting their review to articles only written in English. Third, knowledge about problem gambling and problem gambling treatment needs to reach broader, more diverse professional audiences to ensure those with gambling problems receive adequate help when they seek treatment from any mental health or medical provider and future studies could include a more thorough review of grey literature that span multiple fields of study.

\section{References}

Abbot, D. A., Cramer, S. L., \& Sherrets, S. D. (1995). Pathological gambling and the family: Practice implications. Families in Society: The Journal of Contemporary Social Services, 76(4), 213219. https://doi.org/10.1177/104438949507600402

Abbott, M. W. (2019a). Professional delivered interventions for gambling disorder. Current Opinion in Psychiatry, 32(4), 313-319. https://doi.org/10.1097/YCO.0000000000000516

Abbott, M. W. (2019b). Self-directed interventions for gambling disorder. Current Opinion in Psychiatry, 32(4), 307-312. https://doi.org/10.1097/YCO.0000000000000515

Barak, A. \& Grohol, J. (2011). Current and future trends in internetsupported mental health interventions. Journal of Technology in Human Services, 29(3), 155-196, https://doi.org/10.1080/15228835.2011.616939 
Blaszczynski, A. \& Nower, L. (2002). A pathways model of problem and pathological gambling. Addiction, 97(5), 487-499. https://doi.org/10.1046/j.1360-0443.2002.00015.x

Christensen, J., McDowell, T., \& Kosutic, I. (2022). A critical review of the scholarly discourse on gambling disorder treatment: Part I. Critical Gambling Studies, 3(1),35-56. https://doi.org/10.29173/cgs96

Cowlishaw, S., Merkouris, S., Chapman, A., \& Radermacher, H. (2014). Pathological and problem gambling in substance use treatment: A systematic review and meta-analysis. Journal of Substance Abuse Treatment, 46(2), 98-105. http://dx.doi.org/10.1016/j.jsat.2013.08.019

Dickerson, M., Hinchy, J., \& England, S. L. (1990). Minimal treatments and problem gamblers: A preliminary investigation. Journal of Gambling Studies, 6(1), 87-101. https://doi.org/10.1007/BF01015751

Doussa, H., Sundbery, J., Cuff, R., Jones, S., \& Goodyear, M. (2017) 'Let's talk about children': Investigating the use of a familyfocused intervention in the gambling support services sector. Australian \& New Zealand Journal of Family Therapy, 38(3), 482495. https://doi.org/10.1002/anzf.1233

Echeburua, E., Amor, P. J., Gomez, M. (2017). Current psychological therapeutic approaches for gambling disorder with psychiatric comorbidities: A narrative review. Salud Mental, 40(6), 299-305. https://doi.org/10.17711/SM.0185-3325.2017.038

Hayer, T., Kalke, J., Meyer, G., \& Brosowski, T. (2018). Do simulated gambling activities predict gambling with real money during adolescence? Empirical findings from a longitudina study. Journal of Gambling Studies, 34(3), 929-947. https://doi.org/10.1007/s10899-018-9755-1

Herd, R. (2006). Mana wahine me te tino rangatiratanga: Mâori women's dignity and self determination. Social Work Review, 18(2), 14-21.

Jiménez-Murcia, S., Tremblay, J., Stinchfield, R., Granero, R., Fernández-Aranda, F., Mestre-Bach, G., Steward, T., del PinoGutiérrez, A., Baño, M., Moragas, L., Aymamí, N., Gómez-Peña, M., Tárrega, S., Valenciano-Mendoza, E., Giroux, I., Sancho, M., Sánchez, I., Mallorquí-Bagué, N., González, V. ... Menchón, J. M. (2017). The involvement of a concerned significant other in gambling disorder treatment outcome. Journal of Gambling Studies, 33(3), 937-953. https://doi.org/10.1007/s10899-0169657-z

Oei, T. S., Raylu, N., \& Casey, L. M. (2010). Effectiveness of group and individual formats of a combined motivational interviewing and cognitive behavioral treatment program for problem gambling: A randomized controlled trial. Behavioural and Cognitive Psychotherapy, 38(2), 233-238. https://doi.org/10.1017/S1352465809990701

Oei, T. P. S., Raylu, N., \& Lai, W. W. (2018). Effectiveness of a self help cognitive behavioural treatment program for problem gamblers: A randomized controlled trial. Journal of Gambling Studies, 34(2), 581-595. https://doi.org/10.1007/s10899-0179723-1

Pasche, S. C., Sinclair, H. Collins, P., Pretorius, A., Grant, J. E., \& Stein, D. J. (2013). The effectiveness of a cognitive-behavioral intervention for pathological gambling: A country-wide study. Annals of Clinical Psychiatry, 25(4), 250-256. https://pubmed.ncbi.nlm.nih.gov/24199214/

Peter, S., Brett, E., Suda, M., Leavens, E., Miller, M., Leffingwell, T., Whelan, J., \& Meyers, A., (2019). A meta-analysis of brief personalized feedback interventions for problematic gambling. Journal of Gambling Studies, 35(2), 447-464. https://doi.org/10.1007/s10899-018-09818-9

Petry, N. M. (2009). Disordered gambling and its treatment. Cognitive and Behavioral Practice, 16(4), 457-467. https://doi.org/10.1016/j.cbpra.2009.02.005

Porche, D. J. (2010). Scholarly discourse. American Journal of Men's Health, 4(3), 185. https://doi.org/10.1177/1557988310380246
Priester, M. A., Brown, T., lachini, A., Clone, S., DeHart, D., \& Seay, K. D. (2016). Treatment access barriers and disparities among individuals with co-occurring and mental health and substance use disorders: An integrative literature review. Journal of Substance Abuse Treatment, 61, 47-59. https://doi.org/10.1016/j.jsat.2015.09.006

Rash, C. J., \& Petry, N. M. (2014). Psychological treatments for gambling disorder. Psychology Research and Behavior Management, 7, 285-295. http://dx.doi.org/10.2147/PRBM.S40883

Richards, D. (2013). Development in technology-delivered psychological interventions. Universitas Psychologica, 12(2), 571579. https://doi.org/10.11144/Javeriana.UPSY12-2.dtdp

Rizeanu, S. (2015). Pathological gambling treatment - review. Procedia - Social and Behavioral Sciences, 187, 613-618. https://doi.org/10.1016/j.sbspro.2015.03.114

Shaffer, H. J., \& Martin, R. (2011). Disordered gambling: Etiology, trajectory, and clinical considerations. Annual Review of Clinical Psychology, 7, 483-510. https://doi.org/10.1146/annurevclinpsy-040510-143928

Smith D. P., Dunn, K. I., Harvey, P. W., Battersby, M. W., \& Pols, R. G. (2013). Assessing randomized clinical trials of cognitive and exposure therapies for gambling disorders: A systematic review. Behaviour Change, 30(3), 139-158. https://doi.org/10.1017/bec.2013.15

Toneatto, T., \& Dragonetti, R. (2008). Effectiveness of communitybased treatment for problem gambling: A quasi-experimental evaluation of cognitive-behavioral vs. twelve-step therapy. The American Journal on Addictions, 17(4), 298-303. https://doi.org/10.1080/10550490802138830

Toneatto, T., \& Gunaratne, M. (2009). Does the treatment of cognitive distortions improve clinical outcomes for problem gambling? Journal of Contemporary Psychotherapy, 39, 221-229. https://doi.org/10.1007/s10879-009-9119-3

Yuan, Y., \& Hunt, R. H. (2009). Systematic reviews: The good, the bad, and the ugly. American Journal of Gastroenterology, 104(5), 1086-1092.

van der Mass, M., Shi, J., Elton-Marshall, T., Hodgins, D. C., Sanchez, S., Lobo, D. S. S., Hagopian, S., \& Turner, N. E. (2019). Internet-based interventions for problem gambling: Scoping review. JMIR Mental Health, 6(1), e65. https://doi.org/10.2196/mental.9419

\section{Funding and Conflict of Interest Statement}

The authors have no conflicts of interest to declare. The authors did not receive any funding for this project.

\section{Author Details}

Iva Kosutic obtained her doctorate in 2010 from the University of Connecticut and is currently an evaluation researcher at Partners in Social Research. Iva has conducted a number of program evaluations, including, most recently, evaluation of the Connecticut Department or Public Health Office of Oral Health programs and a Genomics Office program. Additionally, she has served over the past 10 years as an evaluator for sexuality education programs funded through HRSA's Personal Responsibility Education Program (PREP) grant to the Connecticut Department of Public Health. Iva currently serves as an evaluator for the Connecticut Maternal Mortality Review Program. She taught undergraduate courses at the University of Connecticut, Human Development and Family Sciences Department for 10 years, and graduate courses at Lewis \& Clark College, Marriage, Couples, and Family Therapy Program for 6 years. Her peer-reviewed publications pertain to youth 
development, evaluation of sex ed and youth development programs, gambling treatment and prevention, and marriage and family therapy.

Jeffrey Christensen is an associate professor in the Counseling, Therapy, and School Psychology department at Lewis and Clark College. His scholarship centers on counseling student evaluations and counselor training. Prior to joining academia, he was a clinical co-director of a substance abuse community clinic and provided intensive out-patient therapy for youth in the foster care system.

Dr. McDowell is professor emerita, Lewis \& Clark Graduate School of Education and Counseling. She served as faculty in the Marriage, Couple and Family Therapy program and as former chair of the Department of Counseling, Therapy and School Psychology. Most of Teresa's scholarship has focused on equity-based, socioculturally attuned family therapy. Teresa has worked extensively with the Oregon Department of Health Problem Gambling Services and is co-founder of Lewis \& Clark's Problem Gambling Services. Dr. McDowell currently works with Partners in Social Research doing program evaluation, research, and workforce development. 